OPEN ACCESS

Edited by:

Paula García-Fraile, Academy of Sciences of the Czech Republic (ASCR), Czechia

Reviewed by:

Svetlana Yurgel, Dalhousie University, Canada Kristina Lindström, University of Helsinki, Finland

*Correspondence: Piyush Pandey piyushddn@gmail.com

Specialty section: This article was submitted to

Microbial Symbioses, a section of the journa Frontiers in Microbiology

Received: 12 May 2017 Accepted: 15 September 2017 Published: 27 September 2017

Citation: Devi KA, Pandey G, Rawat AKS, Sharma GD and Pandey P (2017)

The Endophytic

Symbiont-Pseudomonas aeruginosa

Stimulates the Antioxidant Activity and Growth of Achyranthes aspera $L$.

Front. Microbiol. 8:1897.

doi: 10.3389/fmicb.2017.01897

\section{The Endophytic} Symbiont-Pseudomonas aeruginosa Stimulates the Antioxidant Activity and Growth of Achyranthes aspera L.

\author{
Khaidem A. Devi', Garima Pandey ${ }^{2}$, A. K. S. Rawat ${ }^{2}$, Gauri D. Sharma ${ }^{3}$ and \\ Piyush Pandey ${ }^{1 *}$
}

${ }^{1}$ Department of Microbiology, Assam University, Silchar, India, ${ }^{2}$ Pharmacognosy and Ethnopharmacology Division, Council of Scientific \& Industrial Research-National Botanical Research Institute, Lucknow, India, ${ }^{3}$ Bilaspur University, Bilaspur, India

A plant growth promoting bacterial endophyte designated as AL2-14B isolated from the leaves of Achyranthes aspera L. was identified as Pseudomonas aeruginosa based on its phenotypic and physiological features, and 16S rRNA gene sequence analysis. AL214B had plant growth stimulating attributes including siderophore and indole acetic acid release, inorganic phosphate solubilization, along with nitrogenase, ammonification, and protease activities. It also exhibited antifungal property against Rhizoctonia solani. The plantlets grown in germ-free condition were inoculated with AL2-14B and studied for the colonization of endophyte. Significant increase in population of AL2-14B between 3rd and 5th days after inoculation was recorded. The treatment of plants with endophytic $P$. aeruginosa AL2-14B increased nitrogen, phosphorus, potassium (NPK) contents in plant by 3.8, 12.59, and 19.15\%, respectively. Significant enhancement of shoot and root length, dry leaf, dry shoot and dry root weight, and leaf surface area as compared to control $(P<0.05)$ was recorded in AL2-14B inoculated plants. The antioxidant activities increased in plants grown in germ-free conditions and inoculated with AL2-14B. The present study emphasizes on the role of diazotrophic endophyte P. aeruginosa AL2$14 \mathrm{~B}$ in stimulating growth of $A$. aspera $\mathrm{L}$. and improvement of its medicinal properties. Significant increase in growth and antioxidant content of $P$. aeruginosa AL2-14B treated plants suggests the possibility of an economical and eco-friendly mean of achieving antioxidants rich, healthier $A$. aspera plants.

Keywords: Achyranthes aspera, antioxidant, endophyte, PGPB traits, Pseudomonas aeruginosa

\section{INTRODUCTION}

Endophytic bacteria colonize the interior tissue of the plant. They are ubiquitous with a rich biodiversity and unexplored biosynthetic potential (Strobel and Daisy, 2003; Ryan et al., 2009). Endophytes produce a group of bioactive compounds and enzymes to survive in the unique chemical environment of the host plant (Strobel, 2003). Their metabolic activities also help in increasing the growth and development of plants. This is because of direct growth promotion effects of endophytes, through production of plant growth regulators, $\mathrm{N}$-fixation, synthesis of 1-aminocyclopropane-1-carboxylic acid (ACC) deaminase, phosphate solubilization, and/or by 
indirect mechanism of providing resistance to diseases through the production of antimicrobial metabolites or siderophores that inhibit pathogenic microorganisms (Sun et al., 2009; Ji et al., 2014; Abbamondi et al., 2016; Khan et al., 2016). Medicinal plants have beneficial endophyte-plant relationship that may be explored and utilized. Endophytes are considered to be a promising source of novel secondary metabolites (Schulz et al., 2002; Strobel, 2003; Puri et al., 2006) with potential for medicinal use, as well as important in agriculture and industry (Strobel and Daisy, 2003). The anticancer compound (podophyllotoxin; Puri et al., 2006) and the natural insecticide (azadirachtin; Kusari et al., 2012) produced by endophytic microorganisms are good examples for same.

The plant growth promoting properties of endophytes are unique, and therefore it is significant to study such properties from microbial populations linked with medicinally and economically important plants. Achyranthes aspera L (Latjeera; Rough Chaff tree) is a medicinal plant that is used for the dilation of the blood vessels, lowering of the blood pressure, depression of the heart, and increases the rate and amplitude of respiration (Neogi et al., 1970). This plant have been found effective in treating disorders like piles, renal dropsy, pneumonia, cough, kidney stone, skin eruption, snake bites, and dysentery (Aziz et al., 2005). The plant is also reported to have antiperiodic, antiasthmatic (Charyulu, 1982), diuretic (Subramaniam, 1961), purgative, laxative, hepatoprotective (Katewa and Arora, 2001), anti-allergic, and various other important medicinal properties. The pharmacological effects of $A$. aspera L. are attributed to the presence of active compound like alkaloids, saponins, sterols. Other active constituents include D-glucuronic acid, $\beta$-D-galactopyranosyl ester of D-glucuronic acid, oleanolic acid, amino acids, hentriacontane, sapogenin (Khastgir et al., 1958), ecdysterone (Ikan et al., 1971), betaine (Kapoor and Singh, 1966), p-benzoquinone, hydroquinone, spathulenol, nerol, $\alpha$-ionone, asarone, and eugenol (Rameshwar, 2007). Considering the medicinal importance of $A$. aspera, it's pertinent to understand the role of endophytic bacteria on its growth and other properties. Earlier, a root endophyte had been reported (Misra et al., 2012) from $A$. aspera, with focus on its phosphate solubilization activity only. In the present study, endophytic bacteria isolated from the aerial part of $A$. aspera were investigated for their plant growth promoting potential and their effect on antioxidant activity of A. aspera.

\section{MATERIALS AND METHODS}

\section{Isolation of Endophytic Bacteria}

Fresh leaves of $A$. aspera L. plants were collected from different parts of Manipur, India. The leaves were washed with tap water and surface sterilized with $70 \%$ ethanol for $1 \mathrm{~min}$ followed by $0.1 \%$ mercuric chloride for $5 \mathrm{~min}$. Leaves were washed in water, and rinsed in phosphate buffer, macerated in mortar and pestle under aseptic condition. Suitable dilution of $1.0 \mathrm{~g}$ of macerated tissue was plated on yeast extract mannitol agar (YEMA) and incubated at $30^{\circ} \mathrm{C}$ for 3 days. The bacterial colonies were selected, sub-cultured, purified, and used for further studies.

\section{Morphological and Biochemical Characterization of the Isolates}

The isolates were characterized for morphological and biochemical properties according to Bergey's Manual of Systematic Bacteriology (Bergey et al., 1994). Colony morphology, shape, color, and growth pattern were recorded after $24 \mathrm{~h}$ of growth on YEMA. The isolates were also tested for catalase (Aneja, 2006), oxidase (Cappuccino and Sherman, 1996), citrate, indole production (Seeley and VanDemark, 1981), and carbohydrate fermentation test (Aneja, 2006).

\section{Molecular Characterization of the Isolates}

The genomic DNA of isolates was extracted using HiPurA Bacterial Genomic Purification Kit (Hi-Media). The primers 27F (5'-CAGAGTTTGATCCTGGCT-3') and 1492R (5'-AG GAGGTGATCCAGCCGCA-3') were used for amplification of 16S rRNA gene (Weisburg et al., 1991). The total PCR mixture was $25.0 \mu \mathrm{L}$ comprising $2 \times$ Master mix (GCC Biotech), $12.5 \mu \mathrm{L}$; 27F, $1.0 \mu \mathrm{L}$; 1492R, $1.0 \mu \mathrm{L}$; lysate DNA, $1.0 \mu \mathrm{L}$, and nuclease free Milli-Q water, $9.5 \mu \mathrm{L}$. The PCR condition was an initial denaturation at $94^{\circ} \mathrm{C}$ for $5 \mathrm{~min}$, followed by 30 cycles of $94^{\circ} \mathrm{C}$ for $30 \mathrm{~s}, 55^{\circ} \mathrm{C}$ for $30 \mathrm{~s}$, and $72^{\circ} \mathrm{C}$ for $1.30 \mathrm{~min}$ and final extension at $72^{\circ} \mathrm{C}$ for $10 \mathrm{~min}$. Five microliters of purified PCR product was loaded in the agarose gel (1\%) while $1 \mu \mathrm{L}$ DNA ladder (100 bp) (Promega) was also loaded to estimate the size of the amplified fragments. The gel was run at $100 \mathrm{~V}$ for about $90 \mathrm{~min}$ and observed under the UV transilluminator for possible amplification. The amplified 16S rRNA gene was sequenced (Xcelris Labs Ltd, India), and identified using the EzTaxon-e server database (Kim et al., 2012) and NCBI GenBank databases. It was aligned with the $16 \mathrm{~S}$ rRNA gene sequences of other related species using CLUSTAL X v2.1 (Larkin et al., 2007). Phylogenetic analyses were performed using the software package MEGA 4 (Tamura et al., 2011).

\section{Pathogenicity of Isolate}

The isolate Pseudomonas aeruginosa AL2-14B was subjected for "hemolytic activity" assay, and screening for virulence genes to check if it may be potentially pathogenic. The isolate was spotinoculated on blood agar plates and incubated at $37^{\circ} \mathrm{C}$ for $48 \mathrm{~h}$ to determine its ability to release hemolytic cytotoxin. The plates were checked for appearance of zones for complete or partial hemolytic activity. Further, virulence genes-toxA (270 bp) for exotoxin and plcH (608 bp) for hemolysin-were screened by PCR amplification (Sabharwal et al., 2014), where $25 \mu \mathrm{L}$ reaction mixtures had $2.5 \mu \mathrm{L}$ of dNTPs $(10 \mathrm{mM}), 1.25 \mu \mathrm{L}$ each of forward and reverse primers ( 5 pmol each), $2.5 \mu \mathrm{L} 10 \times$ PCR buffer and $0.25 \mu \mathrm{L}$ Taq DNA polymerase $(3 \mu \mathrm{L})$. The following gene-specific primers were used: (a) toxA F (CTGCGCGGGTCTATGTGCC) and toxA $\mathrm{R}$ (GATGCTGGACGGGTCGAC), (b) plcH F (GCACGTGGTCATCCTGATGC) and plcH R (TCCGTAG GCGTCGACGTAC). PCR conditions remained as initial denaturation at $95^{\circ} \mathrm{C}$ for $7 \mathrm{~min}, 30$ cycles of denaturation at $95^{\circ} \mathrm{C}$ for $1 \mathrm{~min}$, annealing at 52 or $53^{\circ} \mathrm{C}$ for $1 \mathrm{~min}$ (for tox $\mathrm{A}$ or $\mathrm{plcH}$, respectively), and extension at $72^{\circ} \mathrm{C}$ for $30 \mathrm{~s}$, followed 
by a final extension at $72^{\circ} \mathrm{C}$ for $10 \mathrm{~min}$. Clinical $P$. aeruginosa isolates-C82, A135, and C69-were used as positive control.

\section{Siderophore Production Assay}

The ability of isolates to produce siderophore was determined by formation of orange halo around bacterial colonies on Chrome Azurol S (CAS) agar plates incubated at $30^{\circ} \mathrm{C}$ for $48 \mathrm{~h}$ (Schwyn and Neilands, 1987). The cultures were inoculated in iron-deficient CAS liquid medium (Schwyn and Neilands, 1987) and incubated on rotary shaker at $120 \mathrm{rpm}$. Quantitative estimation of siderophores was done by CAS-shuttle assay. One milliliter of culture supernatant was mixed with $1 \mathrm{~mL}$ of CAS reagent (10 mM HDTMA; $1 \mathrm{mM} \mathrm{FeCl}_{3}$ solution; $2 \mathrm{mM}$ CAS solution) and absorbance was measured at $630 \mathrm{~nm}$ against a reference, having $1 \mathrm{~mL}$ of uninoculated broth and $1 \mathrm{~mL}$ of CAS reagent (Payne, 1994). The activity was recorded in "percentage siderophore units" calculated as [( $\left.\left.\mathrm{Ar}-\mathrm{As}) \times \mathrm{Ar}^{-1}\right) \times 100\right]$. Where, Ar is the absorbance of reference at $630 \mathrm{~nm}$ (uninoculated media + CAS reagent) and As is the absorbance of sample at $630 \mathrm{~nm}$ (culture supernatant + CAS reagent). The type of siderophore produced (catecholate or hydroxamate) was determined according to Arnow's (1937) and $\mathrm{FeCl}_{3}$ tests (Meyer et al., 1995).

For the determination of the threshold level of iron for siderophore production, iron content of succinic medium (Sayyed et al., 2005) was varied by the addition of ferric chloride in the range of $0-30 \mu \mathrm{M}$ concentration. Bacterial strain was inoculated and incubated at $29^{\circ} \mathrm{C}$ at $120 \mathrm{rpm}$, and siderophore content was estimated as described above. The siderophore production was quantified twice, each with three replicates.

\section{IAA Production Assay}

The indole acetic acid (IAA) production was determined by the method of Loper and Scroth (1986). The isolates were grown on YEMA medium for 5 days. A loopful of the culture was inoculated in different flasks having YEM broth, each supplemented with a different L-tryptophan concentration $(0,0.2,0.4,0.6,0.8$, or $1.0 \%)$ and incubated at rotatory shaker $\left(150 \mathrm{rpm}, 30^{\circ} \mathrm{C}\right)$. Production of IAA was measured after every $24 \mathrm{~h}$ interval. The cultures were harvested by centrifugation $(11,000 \times g, 15 \mathrm{~min}), 1 \mathrm{~mL}$ of the supernatant was mixed with $2 \mathrm{~mL}$ of Salkowski reagent $(50 \mathrm{~mL}$, $35 \%$ perchloric acid with $1 \mathrm{~mL}, 0.5 \mathrm{M} \mathrm{FeCl} 3$ ) (Gordon and Weber, 1951). Optical density (OD) was measured at $530 \mathrm{~nm}$ and the amount of IAA produced was quantified by comparing with the standard curve prepared with known concentrations of IAA. The IAA release was quantified twice, each with three replicates.

\section{Phosphate Solubilization, Nitrogen Fixation, and ACC Deaminase Production}

The ability of isolates to solubilize inorganic phosphate was assayed using modified Pikovskaya medium (Nautiyal, 1999). The halo and colony diameter were measured every $24 \mathrm{~h}$ up to 4 days of incubation at $30^{\circ} \mathrm{C}$. The solubilization index has been defined as the ratio of the total diameter (colony + halo zone) to the colony diameter (Premono et al., 1996). Quantitative estimation of $\mathrm{P}$ content in the supernatant was estimated using the vanado-molybdate colorimetric method (Koenig and Johnson, 1942).

Ability to fix atmospheric nitrogen was screened in nitrogenfree combined carbon (NFCC) supplemented with $0.5 \mathrm{mM}$ glucose (Mirza and Rodrigues, 2012), where semisolid NFCC medium $(0.5 \%$ agar $)$ was inoculated with test strain and incubated under atmospheric conditions. Nitrogenase activity was determined by acetylene reduction assay to confirm nitrogen fixation ability of isolate by using GC-FID (Hardy et al., 1971). Further, nifH gene was amplified, with a set primer nifH F: 5'-CGTTTTACGGCAAGGGCGGTATCGGCA-3' and nifH R: 5'-TCCTCCAGCTCCTCCATGGTGATCGG-3'. PCR conditions for the amplification of nifH gene fragment was denaturation at $94^{\circ} \mathrm{C}$ for $5 \mathrm{~min}$ followed by 30 cycles of denaturation at $94^{\circ} \mathrm{C}$ for $1 \mathrm{~min}$, primer annealing at $51-57^{\circ} \mathrm{C}$ for $30 \mathrm{~s}$, and elongation at $72^{\circ} \mathrm{C}$ for $1 \mathrm{~min}$ followed by a final step of extension at $72^{\circ} \mathrm{C}$ for $5 \mathrm{~min}$. Amplified PCR products were resolved on $1 \%$ agarose gel. Klebsiella pneumoniae S4C9 was experimented in parallel for nifH amplification as positive control. ACC deaminase activity was screened according to ElTarabily (2008) using the nitrogen-free Dworkin and Foster's minimal salts agar medium (Dworkin and Foster, 1958). The solid medium was supplemented with either $2 \mathrm{~g}\left(\mathrm{NH}_{4}\right)_{2} \mathrm{SO}_{4}$ or $3 \mathrm{mM}$ ACC per liter as sole nitrogen source, and incubated aerobically. The growth experiment was conducted twice, on five plates, at each attempt.

\section{Antifungal Activity}

The antifungal activity of the isolates was tested in vitro against three strains of pathogenic fungi, i.e., Rhizoctonia solani, Fusarium oxysporum, and Pyricularia oryzae. The antifungal bioassays were performed using dual culture method (Khamna et al., 2009). Three days old culture was spot inoculated at the corners of the PDA plates leaving some distance from the margins. Fungal plug $(6 \mathrm{~mm})$ was then placed at the center of the plates. The plates were incubated at $30^{\circ} \mathrm{C}$ for 5 days. Plates containing fungal plugs without the isolates were used as control. The inhibition zone was measured after the fungal mycelia in the control plates reached the edges of the plates. Growth inhibition was calculated using the formula:

Percentage of growth inhibition $=[(C-T) / C] \times 100$ where, $C$ is the radial growth of the test pathogen in the control plates ( $\mathrm{mm}$ ), and $T$ is the radial growth of the test pathogen in the test plates $(\mathrm{mm})$. The dual-culture assay was conducted twice, on three plates, at each attempt.

\section{Pot Trial Experiment for Assessment of Colonization, and Growth Stimulating Effect of AL2-14B in Experimentally Inoculated Plants}

Micropropagated plantlets of $A$. aspera were raised from the surface sterilized seeds on half strength Murashige and Skoog (MS) medium. The seeds of A. aspera were placed in the Petri dishes containing $25 \mathrm{~mL}$ sterilized half strength of MS medium and incubated at $60 \%$ humidity, $24 \pm 2{ }^{\circ} \mathrm{C}$ and 1000 lux light 
(16 h light and $8 \mathrm{~h}$ dark). After 4 weeks, when the seedlings have cotyledons and roots, they were transferred to freshly prepared MS medium and allowed to grow. After development of extensive root system and with six leaflets, the plantlets were gradually acclimatized to natural environment and finally planted in sterile soil under greenhouse conditions $\left(26 \pm 2^{\circ} \mathrm{C}\right.$ and $\left.70 \% \mathrm{RH}\right)$.

Bacteria were grown to the mid-log phase, and harvested by centrifugation $\left(6000 \times g, 10 \mathrm{~min}, 24^{\circ} \mathrm{C}\right)$. Pellets were washed twice, and suspended in sterilized double distilled water. The suspension was maintained at the $\mathrm{OD}_{600}$ of 1.0. To confirm inoculation density and purity, an aliquot of culture was serially diluted in sterile double distilled water and plated on YEMA medium. The plants were inoculated (in triplicate), when a minimum height of $7.5 \mathrm{~cm}$ was attained and the stalks were at least $0.5 \mathrm{~cm}$ in diameter, which corresponded to 75-80 days after seed germination. A 26-gauge needle attached to a tuberculin syringe containing a bacterial suspension was passed horizontally through the stem just above the first cotyledon leaves of the plant. A $10 \mu \mathrm{L}$ droplet of suspension was formed at the tip of the needle, which was withdrawn through the plant stem.

AL2-14B was experimented for its colonizing behavior in aerial region of $A$. aspera. It was inoculated, and re-isolated for estimation of population density, from stem and leaves of experimentally inoculated $A$. aspera seedlings. Morphological and physiological characteristics of the re-isolated endophytic bacterium were compared to assure it to be AL2-14B. Isolates were further confirmed to be $P$. aeruginosa AL2-14B based on $16 \mathrm{~S}$ rRNA sequence similarity. A $10 \mu \mathrm{L}$ of AL2-14B suspension $\left(\mathrm{OD}_{600}=1.0\right.$, which corresponded to $\left.12.9 \times 10^{5} \mathrm{CFU} / \mathrm{mL}\right)$, was inoculated into the plant hosts and grown in the greenhouse condition. The bacterial multiplication in the stem and leaves of plants were determined at 3 and 5 days after inoculation (DAI). Lower parts of stems and first leaves were collected from three replicates, weighed, and surface sterilized in $70 \%$ ethanol for $15 \mathrm{~s}$, rinsed with double distilled water and macerated with $1 \mathrm{~mL}$ of sterile double distilled water. After $20 \mathrm{~min}$, the supernatant were serially diluted and plated on YEMA amended with $25 \mu \mathrm{g} / \mathrm{mL}$ of kanamycin and incubated at $28^{\circ} \mathrm{C}$ for $48 \mathrm{~h}$. The control plants were inoculated with sterile double distilled water by using the methods used for the experimental plants. Kanamycin was used for screening against any contamination (if any) for AL2-14B, as it was found to be resistant for kanamycin.

Further, the acclimatized plantlets were transferred into bigger pot having diameter of $25 \mathrm{~cm}^{2}$ and depth of $20 \mathrm{~cm}$. The pot has the capacity of holding $5 \mathrm{~kg}$ of soil:sand (4:1) and kept at randomized block design. The plants were watered every alternative day. The plants were harvested after 150 days and different growth parameters such as shoot length, root length, numbers of leaves, fresh leaf weight, fresh shoot weight, fresh root weight, dry leaf weight, dry shoot weight, dry root weight, and area of the leaf were measured.

\section{Availability and Uptake of NPK}

Availability of nitrogen, phosphorus, potassium (NPK) in soil, for each treatment was analyzed at initial stage, and after 30 days. Effect of AL2-14B on nutrient uptake of A. aspera L. was analyzed in the leaves of 30 days old seedlings. Total $\mathrm{N}$ was estimated by
Kjeldahl digestion method, total $\mathrm{P}$ in plant samples was estimated by ammonium molybdate method; whereas $\mathrm{K}$ was analyzed by flame photometric method.

\section{Experimental Design and Statistical Analysis for Pot Trials}

The pot trial experiment had two treatments (with and without bacterial inoculation) each with three replicates having five plants in each pot and arranged in a completely randomized design. All data were subjected to one-way analysis of variance (ANOVA) followed by independent $t$-test at $P<0.05$ using the SPSS 16 software (SPSS Inc). The CFU data were subjected to single factor ANOVA or $t$-test (assuming equal variance) using the SPSS 16 software (SPSS Inc.). The mean \pm standard deviation values are presented.

\section{Scavenging Effect on DPPH Free Radical}

The leaves samples were cleaned, dried, and powered with the help of mixer grinder. The powered leaves were extracted with ethanol and water using soxhlet apparatus at $55-85^{\circ} \mathrm{C}$ for $8-10 \mathrm{~h}$. The free radical scavenging activity of $50 \%$ aqueous ethanolic extract of $A$. aspera L. on stable radical 1,1-diphenyl-2picrylhydrazyl (DPPH) was evaluated by the method of BrandWilliams et al. (1995). Briefly, $2.0 \mathrm{~mL}$ of extract at different concentrations $(50-250 \mu \mathrm{g} / \mathrm{mL})$ was mixed with $2.0 \mathrm{~mL}$ of DPPH solution in methanol $(0.004 \% \mathrm{w} / \mathrm{v})$. The mixture was allowed to stand at room temperature in dark for $20 \mathrm{~min}$. The mixture was vortexed and then absorbance was recorded at $517 \mathrm{~nm}$. Ascorbic acid was used as a reference standard and control consisted of DPPH solution without extract. The test was performed in triplicate and percentage scavenging of DPPH free radical by extract was calculated using the equation: $\left[\left(A_{\text {control }}-A_{\text {test }}\right) A_{\text {control }}{ }^{-1}\right] \times 100$. Here, $A_{\text {control }}$ was the absorbance of control and $A_{\text {test }}$ was the absorbance in presence of extract or standard. Mean of three determinations was recorded.

\section{$\beta$-Carotene-Linoleic Acid Assay}

$\beta$-Carotene bleaching assay was done according Wettasinghe and Shahidi (1999). One milliliter of $\beta$-carotene solution $(0.2 \mathrm{mg} / \mathrm{mL}$ in chloroform) was pipetted into a round bottom flask containing $0.02 \mathrm{~mL}$ of linoleic acid and $0.2 \mathrm{~mL}$ of $100 \%$ Tween-20. The mixture was evaporated in a rotary vacuum evaporator for $10 \mathrm{~min}$ to remove chloroform. The mixture was immediately diluted with $100 \mathrm{~mL}$ of distilled water with vigorous shaking to form an emulsion. Varying concentrations of extract and standard $(100-500 \mu \mathrm{g} / \mathrm{mL})$ was added to $5 \mathrm{~mL}$ of the emulsion in different test-tubes and the mixture was kept at $37^{\circ} \mathrm{C}$ for $1 \mathrm{~h}$. Absorbance of sample and control was measured at time $t=0$ and $t=60 \mathrm{~min}$. Total antioxidant activity was calculated based on the following equation: $\mathrm{AA}=\left[1-\left(A_{0}-A_{\mathrm{t}}\right) \times\left(A_{0}{ }^{0}-A_{\mathrm{t}}{ }^{0}\right)^{-1}\right] \times 100$, where AA is antioxidant activity, $A_{0}$ and $A_{0}{ }^{0}$ are the absorbance values measured at the initial incubation time for samples and control, respectively while $A_{\mathrm{t}}$ and $A_{\mathrm{t}}{ }^{0}$ are the absorbance values measured in the samples or standards and control at $t=60 \mathrm{~min}$. Mean of three determinations was recorded. 


\section{Determination of Reducing Power}

The reducing power of leaves extract was determined by the method of Jayanthi and Lalitha (2011). Substances possessing reducing power react with potassium ferricyanide $\left(\mathrm{Fe}^{3+}\right)$ to form potassium ferrocyanide $\left(\mathrm{Fe}^{2+}\right)$ which then reacts with ferric chloride to form ferric ferrous complex that has an absorption maximum at $700 \mathrm{~nm}$. Varying concentrations of plant extract and standard $(50-250 \mu \mathrm{g} / \mathrm{mL})$ were mixed with phosphate buffer $(2.5 \mathrm{~mL})$ and potassium ferrocyanide $(2.5 \mathrm{~mL})$. The mixture was kept at water bath at $50^{\circ} \mathrm{C}$ for $20 \mathrm{~min}$. After cooling $2.5 \mathrm{~mL}$ of $10 \%$ trichloroacetic acid was added and centrifuged at $3000 \times g$ for $10 \mathrm{~min}$. The upper layer $(2.5 \mathrm{~mL})$ of the resulting solution was mixed with distilled water $(2.5 \mathrm{~mL})$ and freshly prepared ferric chloride solution $(0.5 \mathrm{~mL})$. The absorbance was measured at $700 \mathrm{~nm}$. Ascorbic acid at various concentration was taken as standard. Increase in absorbance indicated the increase in reducing power of extract as compared to standard. Mean of three determinations was recorded.

\section{RESULTS}

\section{Isolation and Characterization of Endophytic Isolate AL2-14B}

Seventy-three isolates were obtained from different area of Manipur, India, as endophytic bacteria from the leaves and stems of A. aspera. One of the isolate, AL2-14B was selected for this study because of its excellent plant growth stimulating attributes. AL2-14B was Gram-negative, catalase and oxidase positive, small rod that forms irregular greenish-brown, circular, and smooth colonies on YEMA. It fermented glucose and lignin but found negative for other carbohydrates such as fructose, mannitol, sucrose, cellulose, and maltose. It was indole negative, methyl red negative, Voges-Proskauer negative and Simmons' citrate positive. The results of the BLAST analysis of the $1200 \mathrm{bp}$ long 16S rRNA gene sequence indicated that AL2-14B isolate is closely related to $P$. aeruginosa. Based on the phylogenetic tree constructed with the $16 \mathrm{~S}$ rRNA similarity (\%), it was identified as $P$. aeruginosa, and maximum similarity was observed with isolate $P$. aeruginosa JCM 5962T/BAMA01000316 (Figure 1). Strain AL2-14B clustered with Pseudomonas indica and P. aeruginosa. 16S rDNA sequence of strain AL2-14B was submitted to GenBank under accession no. KY0879823.1

The isolate did not show any hemolytic activity on blood agar medium suggesting it to be non-producer of hemolytic cytotoxin. PCR-based screening also confirmed it to be negative for tox $\mathrm{A}$ and $\mathrm{plcH}$ genes, which has been suggested as marker for pathogenic strains of $P$. aeruginosa (Sabharwal et al., 2014).

\section{Siderophore Production Assay}

Formation of orange halo zone in CAS medium inoculated with AL2-14B was observed after $24 \mathrm{~h}$, which indicated the production of siderophore. The zone size increased with time. Zone of siderophore produced at $96 \mathrm{~h}$ was found to be $40 \%$ higher than that of zone produced at $24 \mathrm{~h}$. Siderophore release was further

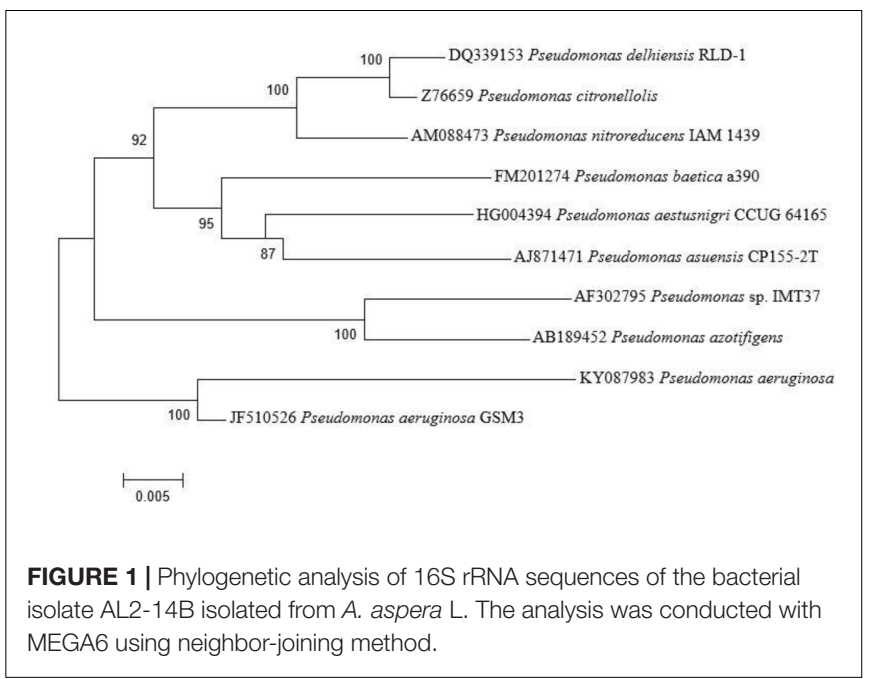

confirmed by quantitative CAS test where instant decolourization of CAS reagent from blue to orange was observed. A total of $71.806 \%$ unit of siderophore was recorded for AL2-14B in succinate broth (Figure 2A). In P. aeruginosa AL2-14B, the siderophore production was found to start after $24 \mathrm{~h}$ of incubation in SM broth and maximum siderophore was released after $72 \mathrm{~h}$ of incubation (71.806\% units) (Figure 2B). It was evident that the siderophore production was high at late log phase, and amount of siderophore release was in accordance with the growth profile of isolate AL2-14B.

\section{Effect of Iron on Siderophore Release}

Siderophore production was considerably affected by the presence of iron in medium. Initial increase in iron concentration induced siderophore production, but further increase in iron concentration resulted in successive decrease of siderophore production by P. aeruginosa AL2-14B. Maximum siderophore release was recorded at $1 \mu \mathrm{M}$ concentration of iron. Siderophore production decreased to $17.74 \mathrm{SU}$ at $10 \mu \mathrm{M}$ of iron and remained almost in the same range for higher concentrations of iron tested (Figure 2C).

\section{IAA Production Assay}

The isolate AL2-14B was screened for the ability to produce IAA. Varying levels of IAA production was recorded with different concentration of L-tryptophan $(0,0.2,0.4,0.6,0.8$, and $1.0 \%)$. The IAA production was in the range of $6.64-$ $114.79 \mu \mathrm{g} / \mathrm{mL}$. A $1.0 \%$ concentration of L-tryptophan was found to be optimum for IAA production by this isolate. IAA production decreased at higher concentrations of tryptophan (Figure 3A). The amount of $1 \mathrm{AA}$ production was maximum after $96 \mathrm{~h}$ of incubation for all the concentrations of tryptophan, except $0.6 \%$ (Figure 3A).

\section{Phosphate Solubilization, Nitrogen Fixation, and ACC Deaminase Activity}

AL2-14B solubilized tri calcium phosphate in Pikovskaya's agar, forming a clear halo around the colony (Figure 3B). 


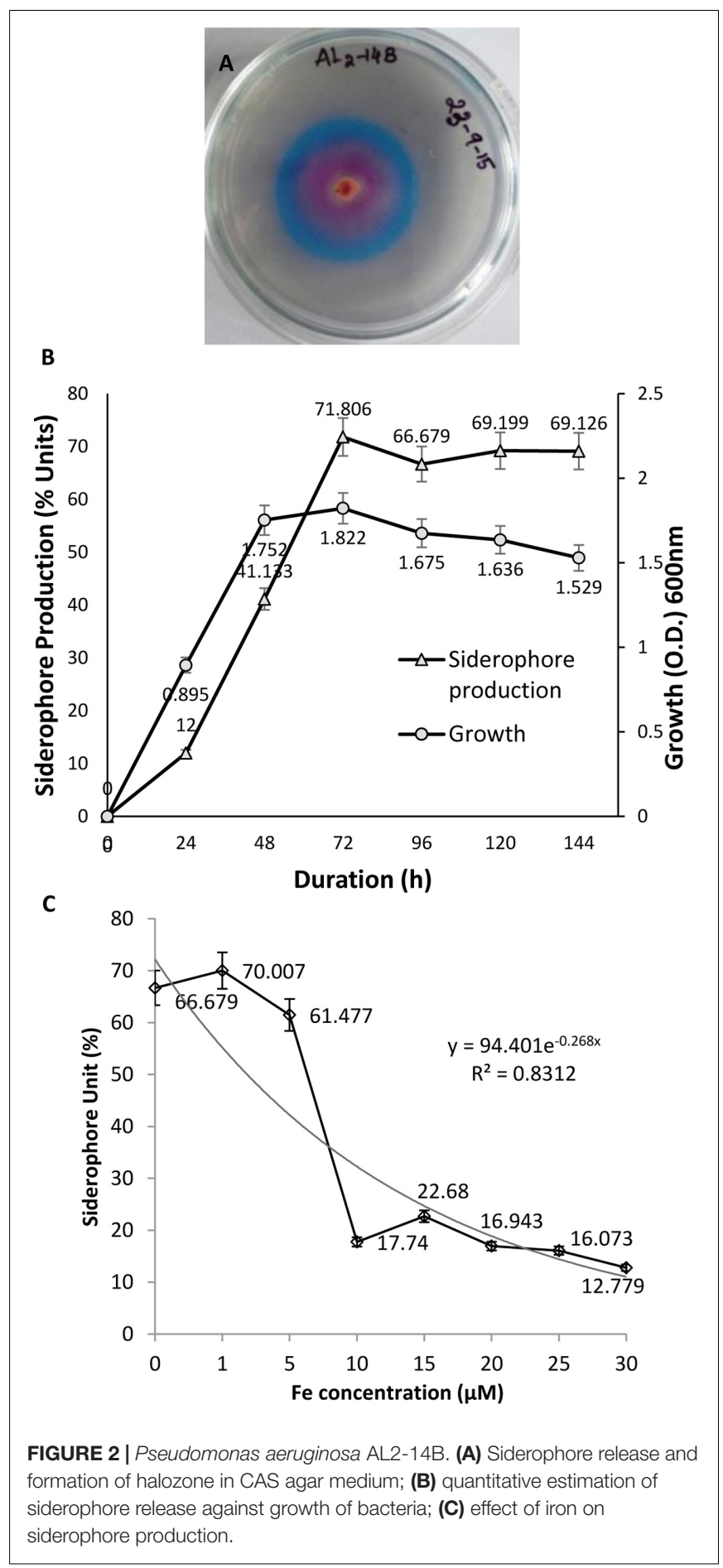

The phosphate solubilization index of the isolate was found to be in the range of $2.33 \pm 0.17$ to $3.66 \pm 0.28$, between 24 and $96 \mathrm{~h}$. The $\mathrm{pH}$ of the medium decreased with increase in the amount of free phosphate released, showing maximum $\mathrm{P}$ solubilization at $\mathrm{pH} 3.9$ after $144 \mathrm{~h}$ of incubation $(383 \mu \mathrm{g} / \mathrm{mL}$ ) (Figure 3B). The correlation coefficient $(r)$ between free $\mathrm{P}$ concentrations against $\mathrm{pH}$ after various durations was calculated and found to be (-) 0.9683 .
Further, the isolate was found to have nitrogen fixation ability. The growth of AL2-14B in NFCC medium, was observed to be close to surface, but not on surface. The ability to fix nitrogen was further confirmed by quantifying Nitrogenase activity, and it was found to be $1.8617 \pm 0.31 \mathrm{nmol}$ ethylene/ $\mu \mathrm{g} / \mathrm{protein} / \mathrm{h}$ as detected using GC-FID technique (Figure 3C). Further, $\mathrm{N}$-fixing ability was confirmed by the presence of nifH gene, and desired amplicon of 781 bp corresponding to nifH gene was obtained in P. aeruginosa AL2-14B (Figure 3C). The isolate was unable to growth on minimal salt medium amended with ACC, which indicate that AL2-14B did not produce ACC deaminase.

\section{Determination of Antifungal Activity}

The isolate AL2-14B showed considerable inhibition of mycelial growth, because of release of diffusible compound(s) against $R$. solani. Percentage of growth inhibition was found to be $68.75 \pm 2.72 \%$ (Figure 4). However, there was no zone of inhibition observed with $F$. oxysporum and $P$. oryzae, suggesting limited antifungal activity in AL2-14B.

\section{Pot Trial Experiment for Assessment of Colonization, and Growth Stimulating Effect of AL2-14B in Experimentally Inoculated Plants}

During in vitro propagation of $A$. aspera in germ free condition, $29 \%$ of seeds germinated in half strength MS medium as compared to full strength MS medium, in which only $22 \%$ seeds germinated. Better germination was observed in seeds without husk, as compared to husk coated seeds. The colonization ability of AL2-14B was determined, and it was found that the population of AL2-14B increased from $70 \times 10^{6}$ to $32.3 \times 10^{10} \mathrm{CFU} / \mathrm{g}$ (fresh weight) between 3rd and 5th DAI (Table 1) in stem of seedlings. Further, AL2-14B was not detected in leaves till 3 DAI. However, after $5 \mathrm{DAI}, 11.3 \times 10^{4} \mathrm{CFU} / \mathrm{g}$ of AL2-14B was recovered from leaves of bacteria-treated $A$. aspera plants. The representative control trials yielded no other indigenous bacteria.

Inoculation of endophytic bacteria AL2-14B in host plant resulted increase in all growth parameters of $A$. aspera $\mathrm{L}$. It significantly increased shoot length by $72.83 \pm 1.24 \%$ $(P<0.05)$, fresh shoot weight by $302 \pm 2.74 \%(P<0.05)$, dry shoot weight by $486 \pm 1.43 \%(P<0.05)$, fresh root weight by $385.71 \pm 3.69 \%(P<0.05)$, dry root weight by $700 \pm 3.92 \%(P<0.05)$, and area of leaves by $135.28 \pm 1.6 \%$ $(P<0.05)$ (Table 2 and Figure 5). Further, the NPK concentration, i.e., the availability was estimated in the soil planted with $A$. aspera L. (without inoculation) at the 1 st day and after 30th day of the treatments. It showed that the NPK concentration in soil at the 1st day was $42 \pm 0.63$, $35.42 \pm 2.11$, and $80.5 \pm 2.38 \mathrm{mg} / \mathrm{kg}$, respectively, which was found to decreased in inoculated with AL2-14B. The NPK content in soil in which AL2-14B was inoculated with plants, decreased up to $36 \pm 0.13,33 \pm 0.86$, and $39.2 \pm 0.5 .11 \mathrm{mg} / \mathrm{kg}$, respectively. Again, the uptake of NPK was analyzed by estimating their concentration in the leaves. 

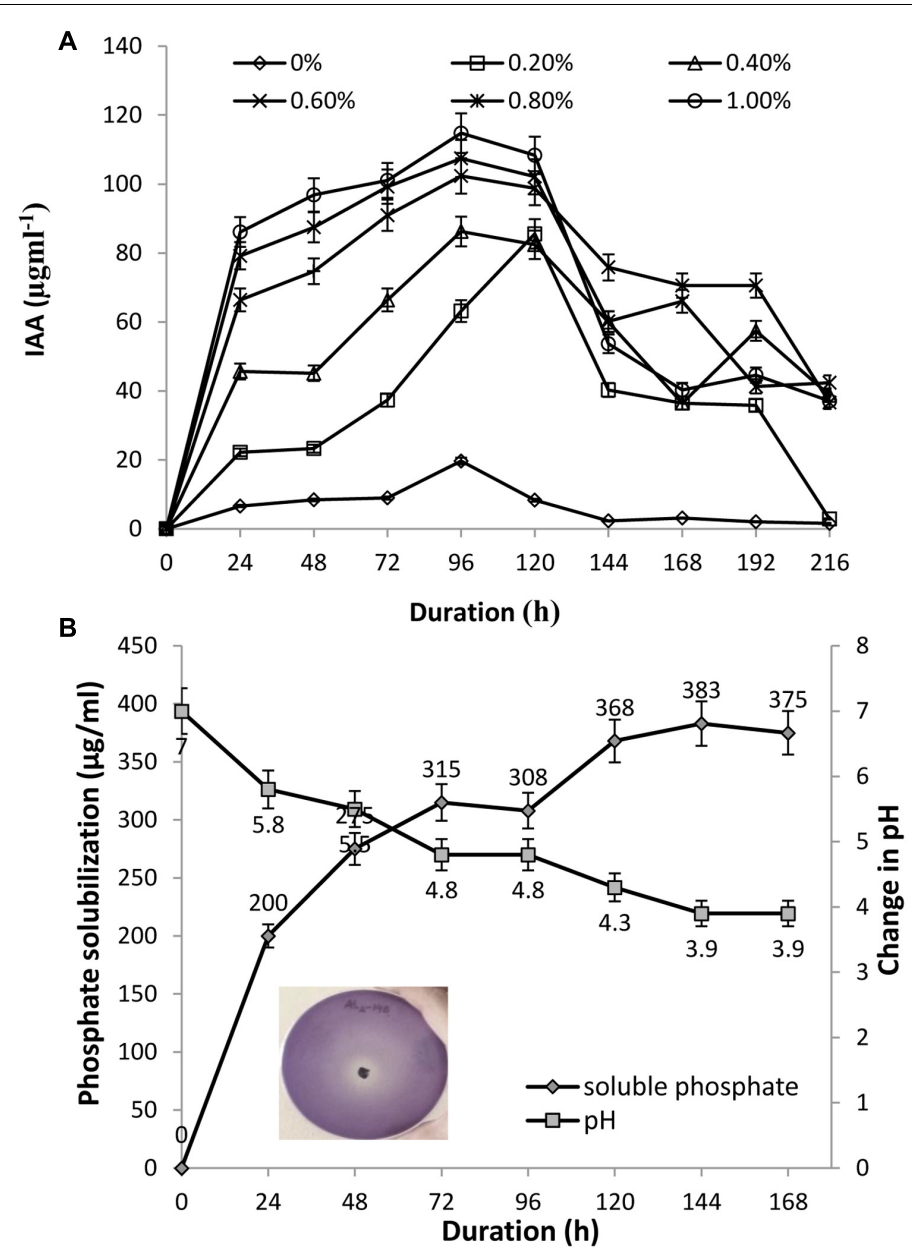

C
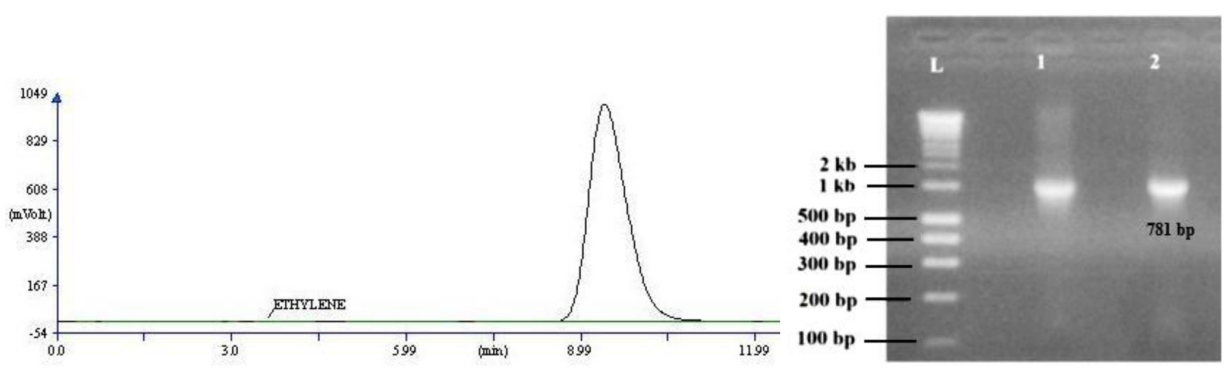

FIGURE 3 | (A) Quantitative estimation of IAA produced by AL2-14B at different L-tryptophan concentrations; (B) phosphate solubilization by AL2-14B after different time intervals. Soluble free phosphate concentration is given against primary $y$-axis, while variation of pH in the culture medium is given at secondary $y$-axis. Standard deviation showed as bars. Photograph represents the zone of clearance around colony of AL2-14B confirming its role in phosphate solubilization; (C) nitrogen fixation: acetylene reduction assay for nitrogenase activity, and nifH amplification (L, ladder; lane 1, Klebsiella pneumoniae S4C9 as positive control; lane 2, AL2-14B).

In the case of control plant (without inoculation), the NPK content in leaves was found to be $29,400 \pm 121,2300.85 \pm 24.2$, and $48,550 \pm 234 \mathrm{mg} / \mathrm{kg}$, respectively. The NPK content in leaves with AL2-14B was significantly higher, recorded as $30,520 \pm 320 \mathrm{mg} / \mathrm{kg}(P<0.05), 2589.64 \pm 64 \mathrm{mg} / \mathrm{kg}$ $(P<0.05)$, and $57850 \pm 199 \mathrm{mg} / \mathrm{kg}(P<0.001)$, respectively. The plants were grown till 150 days for estimation of growth parameters.

\section{Determination of Antioxidant}

\section{Activity-Scavenging Effect on DPPH} Free Radical, $\beta$-Carotene-Linoleic Acid

\section{Assay, and Determination of Reducing} Power

Achyranthes aspera L. plant treated with the isolate AL2-14B showed higher DPPH radical scavenging activity compared to 


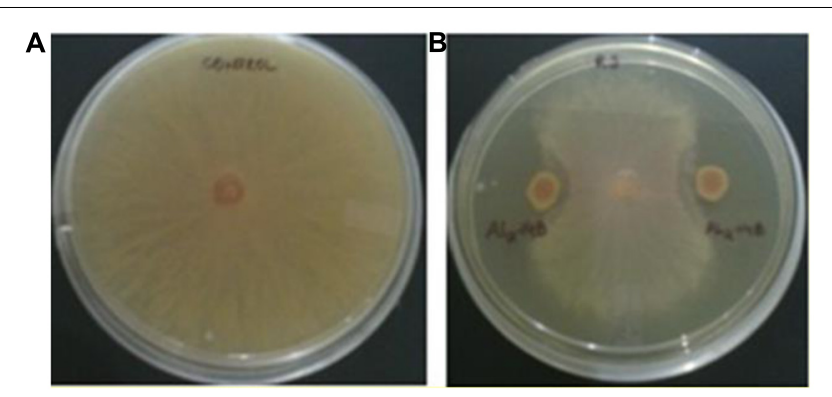

FIGURE 4 | Antagonistic activity of AL2-14B. (A) Control, (B) dual culture assay for assessment of mycelial growth inhibition of Rhizoctonia solani by AL2-14B.

control plant (Figure 6A). The free radical scavenging activity of the extract was concentration dependent. The values of DPPH activity of treated plant ranged from $9.34 \pm 2.12$ to $39.36 \pm 3.26$ while the values of DPPH activity of control plants were in the range of $5.24 \pm 1.28$ to $29.1 \pm 2.52$. IC $_{50}$ was observed at a concentration of $6.41 \pm 0.11 \mathrm{mg} / \mathrm{mL}$ for $\mathrm{DPPH}$ free radical scavenging activity of AL2-14B with the control plant having $\mathrm{IC}_{50}$ of $8.11 \pm 0.24 \mathrm{mg} / \mathrm{mL}$ (Figure 6B).

$\beta$-Carotene-linoleic acid content of extract was found to be more in AL2-14B inoculated plants as compared to control. However, the difference in the activity was not significant $(P<0.05)$. In fact, the activity of the plant treated with AL2-14B ranged from 15.77 to 78.85 while that of un-inoculated control plant were in the range of 15.35-76.76 (Figure 6C).

The reducing power of the plant extract increased with respective increase in concentration. The reducing power of A. aspera L. leaves inoculated with AL2-14B was found to be higher than that of control plant. The values ranged from 0.452 to 1.122 in inoculated plant but in control plant the values were found in the range from 0.342 to 0.951 . For each concentration of extract, the reducing power was found to be significantly higher $(P<0.05)$. The results for reducing power activity of $A$. aspera leaves extract are given in Figure 6D.

\section{DISCUSSION}

Endophytes had been defined in "microbes that settle living, in interior tissues of plants without causing any instant, exert negative effects" (Bacon and White, 2000), but recently, this definition has been elaborated where endophytes have been suggested "to have both positive and negative effect on the plant, as well as they can be neutral to the plant" (Brader et al., 2017). A siderophore producing diazotrophic endophytic $P$. aeruginosa AL2-14B was isolated from the leaves of A. aspera L. Though, a phosphate solubilizing $P$. aeruginosa EPR13 has been reported from the root of $A$. aspera L. (Misra et al., 2012), there has been no earlier reports on exclusive dominance of diazotrophic $P$. aeruginosa endophyte in aerial tissues that affects growth, and antioxidant activities in A. aspera, as described in this report.

Siderophores produced by bacteria contribute in enhancing the growth and yield of agricultural plants. $P$. aeruginosa AL2-14B produced significant amount of siderophore. In fact, $71.806 \%$ unit of siderophore was recorded in succinate broth after $72 \mathrm{~h}$ of incubation. The pattern of siderophore release was correlated with growth, and results were in accordance with similar study on siderophore production reported in Azospirillum (Saxena et al., 1986), where maximum siderophore production was recorded after $20 \mathrm{~h}$ of growth. Pyoverdine type siderophore in P. aeruginosa PAO1 was also found to be released in maximum amount after $40 \mathrm{~h}$ of growth (Barbhaiya and Rao, 1985). Similarly, maximum siderophore production was recorded at the time of commencement of late log phase, which occurred parallel with growth, as observed in previous work (Barbhaiya and Rao, 1985). In bacteria, it has been reported that starvation of iron in medium stimulates siderophore production (Pandey et al., 2005). Therefore, a very low amount of iron was found to induce siderophore production. Further, there was steady decrease in siderophore release, with increase in iron concentrations, which indicate that the siderophore production in AL2-14B is under strict control of iron concentration. The most suitable iron concentration for siderophore production unit was $1 \mu \mathrm{M}$. Sayyed et al. (2005) also found maximum siderophore production at $1 \mu \mathrm{M}$ of iron by P. fluorescens NCIM 5096 and P. putida NCIM2847. In this study, both the Arnow's and $\mathrm{FeCl}_{3}$ tests were positive, revealing the catecholate and hydroxamate type of siderophores. In earlier reports, endophytic $P$. aeruginosa PM389, isolated from the healthy pearl millet plant produced catecholate type of siderophore (63.5\% units) with 0.711 siderophore index (Gupta et al., 2013). Pandey et al. (2005) reported that $P$. aeruginosa GRC1, isolated from mustard plant, produced $18.76 \mu \mathrm{g} / \mathrm{mL}$ of hydroxamate type of siderophore at the iron concentration of $0.2 \mu \mathrm{M}$.

The isolate $P$. aeruginosa AL2-14B was found to release appreciable amount of IAA $(114.79 \mu \mathrm{g} / \mathrm{mL})$, which was induced by L-tryptophan, suggesting that this isolate has tryptophan dependant IAA release mechanism. Maximum IAA was released

TABLE 1 | Population of endophytic bacteria from A. aspera grown in greenhouse condition.

\begin{tabular}{cccc}
\hline Bacteria & Initial population of bacteria as inoculated & Final population of bacteria, CFU/g (fresh weight) & 3 DAI \\
\cline { 2 - 4 } & Stem & Leaf & Stem \\
\hline
\end{tabular}

\begin{tabular}{|c|c|c|c|c|c|}
\hline AL2-14B & $12.9 \pm 0.25 \times 10^{5}(\mathrm{a})$ & $\mathrm{Nil}$ & $70 \pm 0.51 \times 10^{6}(b)$ & $\mathrm{Nil}$ & $32.3 \pm 0.78 \times 10^{10}(\mathrm{c})$ \\
\hline
\end{tabular}

Values with different letter within a row are significantly different from initial population at $P<0.05$. 
TABLE 2 | Effect of $P$. aeruginosa AL2-14B on the growth characteristics of the A. aspera L.

\begin{tabular}{lcr}
\hline Parameters & Control & Inoculated with AL2-14B \\
\hline Shoot length $(\mathrm{cm})$ & $20.54 \pm 2.5(\mathrm{a})$ & $35.50 \pm 0.93(\mathrm{~b})$ \\
Root length $(\mathrm{cm})$ & $10.20 \pm 2.28(\mathrm{a})$ & $22.86 \pm 1.63(\mathrm{a})$ \\
Number of leaves & $9.60 \pm 0.89(\mathrm{a})$ & $20.2 \pm 0.83(\mathrm{a})$ \\
Fresh leaves weight $(\mathrm{g})$ & $0.26 \pm 0.12(\mathrm{a})$ & $0.50 \pm 0.12(\mathrm{a})$ \\
Dry leaves weight $(\mathrm{g})$ & $0.05 \pm 0.023(\mathrm{a})$ & $0.12 \pm 0.03(\mathrm{a})$ \\
Fresh shoot weight $(\mathrm{g})$ & $0.84 \pm 0.14(\mathrm{a})$ & $3.38 \pm 0.64(\mathrm{~b})$ \\
Dry shoot weight $(\mathrm{g})$ & $0.15 \pm 0.02(\mathrm{a})$ & $0.88 \pm 0.43(\mathrm{~b})$ \\
Fresh root weight $(\mathrm{g})$ & $0.21 \pm 0.35(\mathrm{a})$ & $1.02 \pm 0.53(\mathrm{~b})$ \\
Dry root weight $(\mathrm{g})$ & $0.04 \pm 0.005(\mathrm{a})$ & $0.32 \pm 0.17(\mathrm{~b})$ \\
Area of leaves & $24.77 \pm 2.11(\mathrm{a})$ & $58.28 \pm 5.95(\mathrm{~b})$ \\
\hline
\end{tabular}

Each value is the mean of five plants. Values with the same letter within a row are not significant at $P<0.05$.

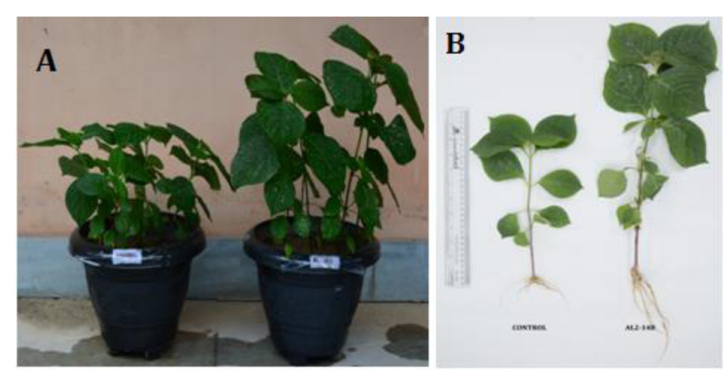

FIGURE 5 | (A,B) Effect of $P$. aeruginosa AL2-14B on growth promotion of A. aspera L.

after $96 \mathrm{~h}$ of incubation, which was in agreement with earlier reports (Sachdev et al., 2009; Khamna et al., 2010). Kumar et al. (2016) reported that $P$. putida ECL5 produced $23 \mu \mathrm{g} / \mathrm{mL}$ of IAA on supplementation of $400 \mu \mathrm{g} / \mathrm{mL}$ of L-tryptophan after $48 \mathrm{~h}$ of incubation. Fouzia et al. (2015) also reported that $P$. fluorescens $\mathrm{CHAO}, P$. fluorescens RB13, and $P$. aeruginosa EH4 produced $88.37,50.95$, and $36.88 \mu \mathrm{g} / \mathrm{mL}$ of IAA after $48 \mathrm{~h}$ of incubation, respectively, with supplement of $5 \mathrm{~g} / \mathrm{L}$ of L-tryptophan.

It is known that bacteria can solubilize inorganic phosphate by releasing organic acids. The carboxylic group of organic acids chelate the cations (mainly $\mathrm{Ca}$ ) bound to phosphates, and thus converting them into the soluble forms (Kpomblekou and Tabatabai, 1994). The isolate P. aeruginosa AL2-14B formed halo zone when inoculated on the Pikovskaya's solid medium containing tri-calcium phosphate. The $\mathrm{pH}$ of the medium decreased with the increase in the amount of free phosphate released, showing maximum $\mathrm{P}$ solubilization at $\mathrm{pH} 3.9$ after $144 \mathrm{~h}$ of incubation (383 $\mu \mathrm{g} / \mathrm{mL})$. Similar results were reported earlier by Kaur and Reddy (2013) with two rhizobacterial isolates of Stevia rebaudiana, namely Pantoea cypripedii PSB-3 and Pseudomonas plecoglossicida PSB-5, which were found to solubilize $253 \mathrm{mg} / \mathrm{mL}$ and $271 \mathrm{mg} / \mathrm{mL}$ of inorganic phosphate, respectively after 5 days of incubation.

Endophytic $P$. aeruginosa AL2-14B was unable to grow on the surface of NFCC medium, but turbidity was observed in deeper regions of culture tubes. This indicates that AL2-14B may fix nitrogen in low oxygen or anaerobic environment only. Earlier, Mirza and Rodrigues (2012) have isolated free living diazotrophic pseudomonads from soil by maintaining hypoxic conditions, and further confirmed it by nitrogenase assay. In acetylene reduction assay, nitrogenase activity was recorded to be $1.8617 \mathrm{nmol}$ ethylene/ $\mu \mathrm{g} /$ protein/h, as estimated using GC-FID technique. Nitrogenase assay is considered as confirmatory test for estimation of nitrogen fixation which is an important attribute for endophytic PGPR. Diazotrophic nature of AL2-14B was further confirmed by the presence of nifH gene element. The presence of nifH in endophytic $P$. aeruginosa has been detected by PCR in previous studies (Gupta et al., 2013). N-fixing endophytic bacteria are considered better than their rhizospheric and rhizoplanic counterparts as they provide fixed nitrogen directly to their host (Cocking, 2003). Moreover, endophytic bacteria are less vulnerable to competition with other soil microbes for scarce resources and remain protected to various abiotic and biotic stresses (Reinhold-Hurek and Hurek, 1998). Earlier, Taule et al. (2012) and Reinhardt et al. (2008) had reported N-fixing endophytic Pseudomonas spp. from sugarcane and maize plants, respectively.

Rhizoctonia solani is a well-known fungal pathogen that causes root rot of several plants. Endophytic bacteria AL2-14B was found to have the ability to inhibit the mycelia growth of pathogenic fungus $R$. solani. Pseudomonads are known for their biocontrol potential against phytopathogens. Earlier, it has been reported that the metabolites produced by $P$. aeruginosa MML2212 inhibited the mycelia growth of $R$. solani (Shanmugaiah et al., 2010). Also, Pseudomonas sp. was used as biocontrol agents for controlling broccoli root rot disease caused by $R$. solani pathogen (El-Mohamedy et al., 2011). This property further improves the utility of $P$. aeruginosa AL2-14B in plant growth, which may be useful in in situ biocontrol of $R$. solani, and need further study. Recently, Egamberdieva et al. (2017) isolated endophytic bacteria from two medicinal plants, Hypericum perforatum and Ziziphora capitata and concluded that antimicrobial activity of medicinal plants is improved by the presence of antagonistic endophytes. The colonization of the bacteria in the host tissues also varied with the plant parts. P. aeruginosa AL2-14B was inoculated in stem tissues, and gradual increase its population was observed in stem. Till 1st 3 days, leaves were not populated by the endophyte, however, after $5 \mathrm{DAI}$, the introduced bacteria were found both in stem $\left(21 \times 10^{6} \mathrm{CFU} / \mathrm{g}\right.$, fresh weight $)$ and leaves $\left(11.3 \times 10^{4} \mathrm{CFU} / \mathrm{g}\right.$, fresh weight $)$ in good numbers. It seems that the bacteria were translocated from stem to leaves through transpiration. This hypothesis is supported by Compant et al. (2005) where he reported that, Burkholderia sp., an endophyte of Vitis vinifera, spread to aerial parts of host plant through the transpiration stream. The upward passive migration of endophytic bacteria possibly through transpiration stream in xylem vessels of stems has been suggested by other workers too (Thorne et al., 2006). However, there are only few reports on experimental greenhouse study of colonization of host plants by bacterial endophytes. For example, $P$. aureofaciens was inoculated 

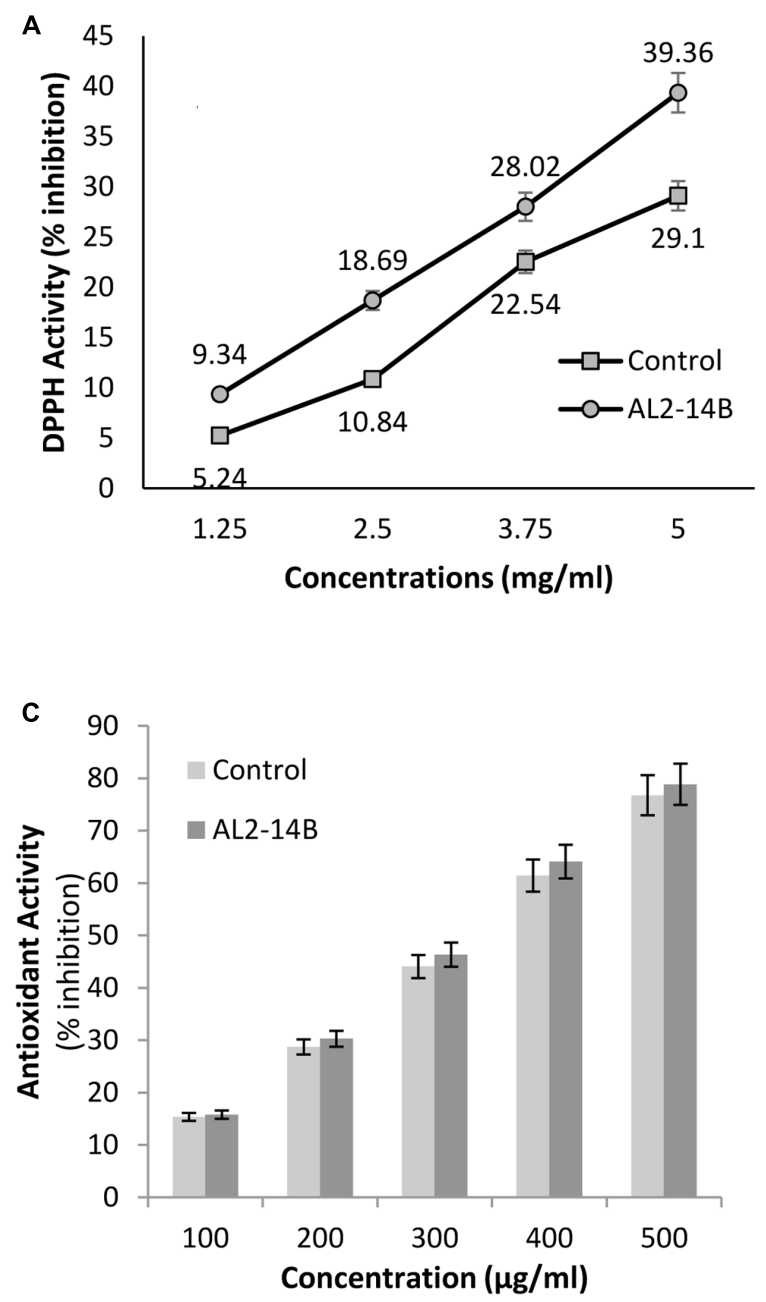
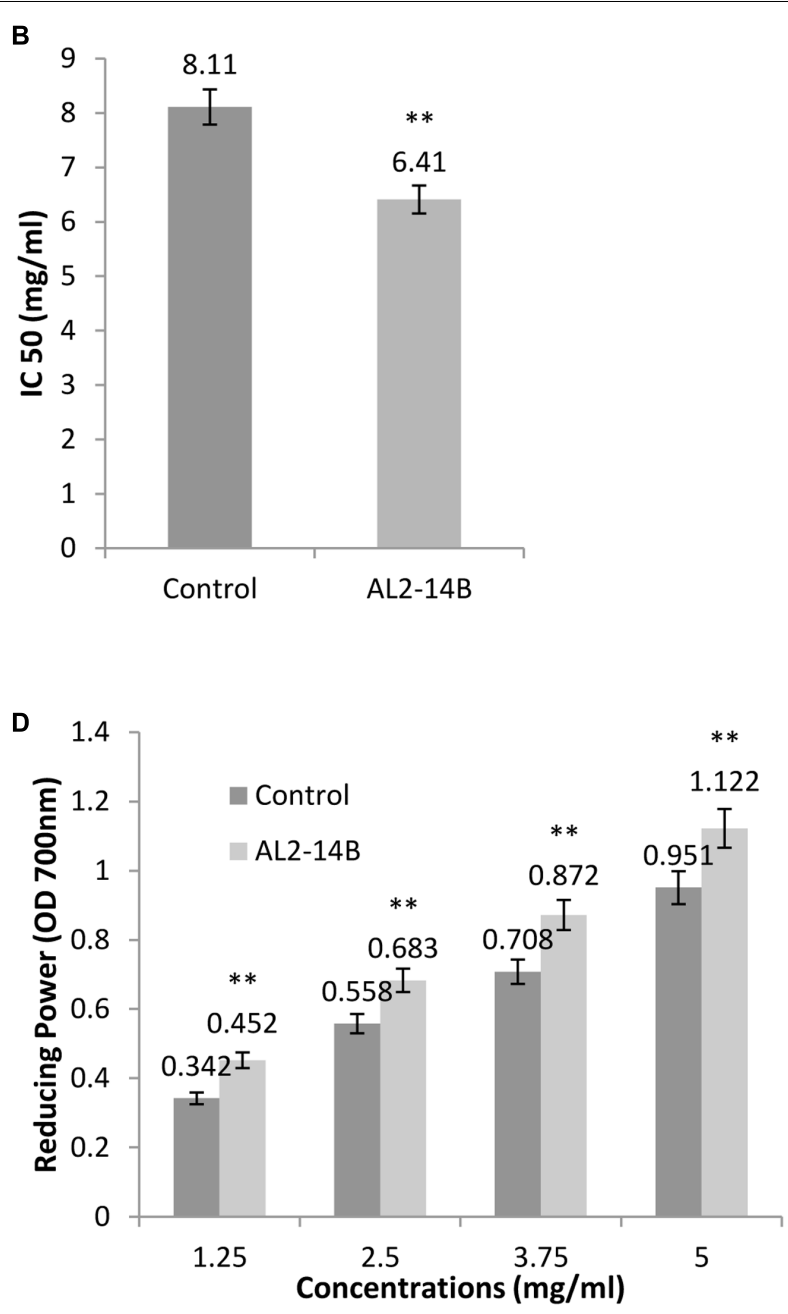

FIGURE 6 | (A) The free radical scavenging activity with DPPH, against different concentrations of $A$. aspera L. extract; (B) concentration of samples that scavenge $50 \%$ free radicals of DPPH, expressed as $\mathrm{IC}_{50}(\mathrm{mg} / \mathrm{mL})$; (C) antioxidant activity of samples using $\beta$-carotene bleaching assay; and (D) reducing power of samples at $700 \mathrm{~nm}$. All results are expressed as mean $\pm \mathrm{SD}$ of three determinations. **Significant at $P<0.05$.

and was recovered after 29 days from tall fescue leaves and pea and bean stems, with population of $2.3 \log 10 \mathrm{CFU} / \mathrm{g}$ (fresh weight) (Lamb et al., 1996). Fisher et al. (1992) reported colonization levels of 2.3-6.5 log CFU/g (fresh weight) of bacteria recovered from field-grown sweet corn. Similarly, Guo et al. (2002) inoculated $4.55 \log \mathrm{CFU} / \mathrm{mL}$ of salmonellae in the roots of tomato plants grown in hydroponic medium, and found that around $3 \mathrm{log} \mathrm{CFU} / \mathrm{g}$ of salmonellae were present in hypocotyls, cotyledons, and stems after $24 \mathrm{~h}$. Though, there is no earlier report on colonization of diazotrophic pseudomonads in aerial tissues of $A$. aspera, the results suggest that its endophytic existence has significant role in overall physiology of A. aspera.

There are few reports, where Pseudomonas sp. has been studied for growth enhancement of Achyranthes. However, these isolates were reported from rhizospheric soil of $A$. aspera (Mohinder et al., 2011; Misra et al., 2012). Here we report an endophytic $P$. aeruginosa, which was isolated from the aerial part of the plant, and promote the growth of the host plant as confirmed by pot trial experiments. The results of pot trials suggest that AL2-14B is an excellent growth promoter of $A$. aspera, as significant increase in growth parameters of plants was recorded. AL2-14B significantly $(P<0.05)$ increased shoot length by $72.83 \%$, fresh shoot weight by $302 \%$, dry shoot weight by $486 \%$, fresh root weight by $385.71 \%$, dry root weight by $700 \%$, and area of leaves by $135.28 \%$. Earlier, Pseudomonas spp. have been reported as endophytic plant growth promoter in few other plants (Dalal and Kulkarni, 2013; Jasim et al., 2013), but not in A. aspera. The treatment of plants with endophytic $P$. aeruginosa AL2-14B increased NPK contents in plant by $3.8,12.59$, and $19.15 \%$, respectively, which was further supported by reduction in NPK content of soil in which these plants were grown. Therefore, endophytic colonization of AL214B also improved the nutrient uptake. The higher values of $\mathrm{N}$ in plants inoculated with AL2-12B may be attributed to its diazotrophic functions (Santoyo et al., 2016). In this study, the 
soil was not supplemented with any kind of chemical fertilizers or pesticide. Therefore, the growth stimulation of host plants, as compared to control, may be credited to the endophytic colonization of $P$. aeruginosa AL2-14B, and its various plant growth stimulating attributes including IAA synthesis, nitrogen fixation, and siderophore production. As a matter of fact, mechanism of plant growth stimulation by interactions of endophyte has been attributed to collective effects of different physiological properties of bacteria, including the production of phytohormones, siderophores, and antifungal compounds (Santoyo et al., 2016), which is also valid for P. aeruginosa AL2-14B.

In spite of concerns related to opportunistic infections caused by $P$. aeruginosa, it is an established plant growth promoting bacteria. P. aeruginosa is known to stimulate growth of host plant indirectly by biocontrol of phytopathogens (Shanmugaiah et al., 2010), induced systemic resistance (Audenaert et al., 2002); or directly by producing siderophore, IAA (Pandey et al., 2005). AL2-14B does not have cytotoxin producing ability and also, it lack two crucial virulent genes. Earlier, Radhapriya et al. (2015) excluded the concern of pathogenicity in $P$. aeruginosa strain RRALC3 isolated from rhizospheric soil by screening for virulence genes ecf $X$, las $B$, and ybtQ.

The antioxidant potentials of $A$. aspera L. substantiate its role as an anticancer agent. Endophytic bacteria help in the mediation of reactive oxygen species and antioxidant activity in plants. Effect of endophytic bacteria AL2-14B was determined on antioxidant activity of $A$. aspera by undertaking several experimental parameters including $\mathrm{DPPH}$ scavenging activity, $\beta$-Carotene-linoleic acid assay, and reducing power of plant extract. It was observed that inoculation of endophytic isolate $P$. aeruginosa, the antioxidant activity of host plant was increased. It has been suggested earlier, that there is a significant impact of endophyte colonization on the antioxidant activity in plants, as antioxidant activities are higher for colonized in comparison to non-colonized host plants (Hamilton et al., 2012). In fact, antioxidants serve to transmit stress signals through the interaction of oxidant and antioxidant (Foyer and Noctor, 2005), which has been suggested to facilitate the chemical communication between the plant and its endophytic symbiont. This process allows the host plant to differentiate a pathogen from a mutualist, and respond accordingly (Hamilton et al., 2012). There are several reports where endophyte colonization of host tissues has been found to alter the production of antioxidants in plants. High antioxidant activities were recorded when Phyllosticta sp. was exposed to reactive oxygen species (Srinivasan et al., 2010). It was suggested that the interaction between endophytic bacteria and host plant affects the host's hypersensitive and systemic acquired resistance responses, which may be mediated by the production of reactive oxygen species and antioxidants (Tanaka et al., 2006). DPPH assay is vital to assess free-radical scavenging ability of antioxidants. In fact, hydrogen-donating ability is an important attribute of the primary antioxidants, which donate hydrogen to free radicals, resulting in formation of non-toxic species (Lugasi et al., 1998;
Sánchez-Moreno et al., 1999). In this study, DPPH activity of the treated plant was found to be higher than the control plant. The free radical scavenging activity of the extract increased with increased in concentration. $\mathrm{IC}_{50}$ of the inoculated plant was observed at $20.96 \%$ lower than that of control plant. $\beta$-Carotene-linoleic acid assay of extract obtained from inoculated plant was found to be slightly higher than the control plant. This assay is based on reaction of $\beta$-carotene with radicals formed by linoleic acid oxidation, resulting in loss of the yellow color. Therefore, low rate of beta carotene bleaching is indicative of presence of antioxidants.

Reducing power serve as a good indicator of antioxidant potential of the plant. Compounds having reducing power are actually electron donors, which reduce the oxidized intermediates of lipid peroxidation. The reducing power of $A$. aspera $\mathrm{L}$ leaves inoculated with AL2-14B was found to be significantly higher than that of control plant. A total of 23 and $18 \%$ increase in the reducing power of the extract were recorded at 3.75 and $5 \mathrm{mg} / \mathrm{mL}$ of extract concentration, respectively. In a different study, Prasad et al. (2013) reported that the medicinal plant Bacopa monnieri treated with root endophytes Piriformo sporaindica DSM 11827 produced higher amounts of bacosides antioxidants than untreated control. The endophyte $P$. indica significantly increased the amount of ascorbic acid and elevated the activities of antioxidant enzymes in barley root under stress conditions (Baltruschat et al., 2008). Therefore, endophytic existence of $P$. aeruginosa AL2-14B was detrimental in affecting the growth of $A$. aspera $\mathrm{L}$, that may be attributed to its growth stimulating attributes like $\mathrm{N}$-fixation, IAA synthesis, siderophore production, and strong antagonistic activity against pathogenic fungus. P. aeruginosa AL2-14B also induced antioxidant activities and therefore enhanced the medicinal value of host plant, which present the prospects of $P$. aeruginosa AL2-14B to be utilized as a biofertilizer in the future. Recently, Song et al. (2017) has reported that Bacillus altitudinis strain LB 5-3, an endophyte isolated from Panax ginseng increases biomass of host plant and improves the medicinal value of plant by eliciting ginsenoside accumulation. Similarly, inoculation of diazotrophic endophytic $P$. aeruginosa was shown to increase in plant growth in Pennisetum glaucum (L.) R. Br. (Gupta et al., 2013), however, here we report it for $A$. aspera. Role of endophytic bacteria in enhancement of the antioxidant activity of $A$. aspera has not been reported earlier.

\section{CONCLUSION}

Pseudomonas aeruginosa AL2-14B, an endophytic isolate from the aerial part of the $A$. aspera L. plant produced good quantity of siderophore, IAA, and solubilized inorganic phosphate. It enhances the growth and antioxidant properties of the host plant. Therefore, isolate AL2-14B have potential to be utilized as a biofertilizer for improvement of plant growth. Because the bioformulations based on endophytic organisms are considered as environment friendly alternative to agrochemicals, AL2-14B 
can be exploited as a growth promoting agent. Further, improved antioxidant activity in $A$. aspera $\mathrm{L}$. is added advantage for the value addition of this medicinal plant.

\section{AUTHOR CONTRIBUTIONS}

KD have performed the growth and symbioses related experiments, wrote manuscript. GP and AR have contributed for

\section{REFERENCES}

Abbamondi, G. R., Tommonaro, G., Weyens, N., Thijs, S., Sillen, W., Gkorezis, P., et al. (2016). Plant growth-promoting effects of rhizospheric and endophytic bacteria associated with different tomato cultivars and new tomato hybrids. Chem. Biol. Technol. Agric. 3, 1. doi: 10.1186/s40538-0150051-3

Aneja, K. R., (2006). Experiments in Microbiology, Plant Pathology and Biotechnology, 4th Edn. New Delhi: New Age International Publishers, 245-275.

Arnow, L. E. (1937). Colorimetric determination of the components of 3, 4Dihydroxyphenylalanine tyrosine mixtures. J. Biol. Chem. 118, 531-537.

Audenaert, K., Pattery, T., Cornelis, P., and Höfte, M. (2002). Induction of systemic resistance to Botrytis cinerea in tomato by Pseudomonas aeruginosa 7NSK2: role of salicylic acid, pyochelin, and pyocyanin. Mol. Plant Microbe Interact. 15, 1147-1156. doi: 10.1094/MPMI.2002.15.11.1147

Aziz, A., Rahman, M., Mondal, A. K., Muslim, T., Rahman, A., and Quader, A. (2005). 3-Acetoxy-6 benzoyloxyapangamide from Achyranthes aspera. Dhaka Univ. J. Pharm. Sci. 4, 113116.

Bacon, C. W., and White, J. F. (2000). Microbial Endophytes. New York, NY: Marcel Dekker Inc., 341-388.

Baltruschat, H., Fodor, J., Harrach, B. D., Niemczk, E., Barna, B., Gullner, G., et al. (2008). Salt tolerance of barley induced by the root endophyte Piriformospora indica is associated with a strong increase in antioxidants. New Phytol. 180, 501-510. doi: 10.1111/j.1469-8137.2008.02583.x

Barbhaiya, H. B., and Rao, K. K. (1985). Production of pyoverdine, the fluorescent pigment of Pseudomonas aeruginosa PA01. FEMS Microbiol. Lett. 27, 233-235. doi: 10.1111/j.1574-6968.1985.tb00673.x

Bergey, D. H., Holt, J. G., Krieg, N. R., and Sneath, P. H. A. (1994). Bergey's Manual of Determinative Bacteriology, 9th Edn, eds R. S. Breed, E. G. D. Murray, and N. R. Smith (Baltimore, MD: Williams and Wilkins).

Brader, G., Compant, S., Vescio, K., Mitter, B., Trognitz, F., Ma, L. J., et al. (2017). Ecology and genomic insights on plant-pathogenic and -nonpathogenic endophytes. Annu. Rev. Phytopathol. doi: 10.1146/annurev-phyto-080516035641 [Epub ahead of print].

Brand-Williams, W., Cuvelier, M. E., and Berset, C. (1995). Use of free radical method to evaluate antioxidant activity. LWT Food Sci. Technol. 28, 25-30. doi: 10.1016/S0023-6438(95)80008-5

Cappuccino, J. G., and Sherman, N. (1996). Microbiology: A Laboratory Manual. New York, NY: The Benjamin/Cummings Publishing Company, 137-149.

Charyulu, G. P. (1982). Effect of Apamarga Achyranthes aspera Antardhooma Bhasma on cases of Tamaka Shwasa Bronchial Asthma. Indian J. Pharm. Sci. 44,31 .

Cocking, E. C. (2003). Endophytic colonization of plant roots by nitrogen- fixing bacteria. Plant Soil 252, 169-175. doi: 10.1023/A:1024106605806

Compant, S., Reiter, B., Sessitsch, A., Nowak, J., Clement, C., and Ait, B. E. (2005). Endophytic colonization of Vitis vinifera L. by plant growthpromoting bacterium Burkholderia sp. strain PsJN. Appl. Environ. Microbiol. 71, 1685-1693. doi: 10.1128/AEM.71.4.1685-1693.2005

Dalal, J., and Kulkarni, N. (2013). Antagonistic and plant growth promoting potentials of indigenous endophytic bacteria of Soybean (Glycine max (L) Merril). Curr. Res. Microbiol. Biotechnol. 1, 62-69.

Dworkin, M., and Foster, J. (1958). Experiments with some microorganisms which utilize ethane and hydrogen. J. Bacteriol. 75, 592-601.

Egamberdieva, D., Wirth, S., Behrendt, U., Ahmad, P., and Berg, G. (2017). Antimicrobial activity of medicinal plants correlates with the proportion antioxidant activities, GS provided important research inputs, PP has designed the work, formulated strategies, and wrote manuscript.

\section{FUNDING}

The work has not been funded by any agency, and part of Ph.D. thesis of KD.

of antagonistic endophytes. Front. Microbiol. 8:199. doi: 10.3389/fmicb.2017. 00199

El-Mohamedy, R. S. R., Abd El-Samad, E. H., Habib, H. A. M., and Fath El-Bab, T. S. H. (2011). Effect of using bio-control agents on growth, yield, head quality and root rot control in Broccoli plants. Int. J. Acad. Res. 3, 71-80.

El-Tarabily, K. A. (2008). Promotion of tomato (Lycopersicon esculentum Mill.) plant growth byrhizosphere competent 1-aminocyclopropane-1-carboxylic acid deaminase-producing streptomycete actinomycetes. Plant Soil. 308, 161-174. doi: $10.1007 / \mathrm{s} 11104-008-9616-2$

Fisher, P. J., Petrini, O., and Scott, H. M. L. (1992). The distribution of some fungal and bacterial endophytes in maize (Zea mays L.). New Phytol. 122, 299-305. doi: 10.1111/j.1469-8137.1992.tb04234.x

Fouzia, A., Allaoua, S., Hafsa, C. S., and Mostefa, G. (2015). Plant growth promoting and antagonistic traits of indigenous fluorescent pseudomonas spp. isolated from wheat rhizosphere and A. halimus endosphere. Eur. Sci. J. 11, 129-148.

Foyer, C. H., and Noctor, G. (2005). Oxidant and antioxidant signalling in plants: a re-evaluation of the concept of oxidative stress in a physiological context. Plant Cell Environ. 28, 1056-1071. doi: 10.1111/j.1365-3040.2005.01327.x

Gordon, A. S., and Weber, R. P. (1951). Colorimetric estimation of indole acetic acid. Plant Physiol. 26, 192-195. doi: 10.1104/pp.26.1.192

Guo, X., Iersel, V., Chen, M. W., Brackett, J. R. E., and Beuchat, L. R. (2002). Evidence of association of salmonellae with tomato plants grown hydroponically in inoculated nutrient solution. Appl. Environ. Microbiol. 68, 3639-3643. doi: 10.1128/AEM.68.7.3639-3643.2002

Gupta, G., Panwar, J., and Jha, P. N. (2013). Natural occurrence of Pseudomonas aeruginosa, a dominant Cultivable diazotrophicendophytic bacterium colonizing Pennisetum glaucum (L.) R.Br. Appl. Soil Ecol. 64, 252-261. doi: 10.1016/j.apsoil.2012.12.016

Hamilton, C. E., Gundel, P. E., Helander, M., and Saikkonen, K. (2012). Endophytic mediation of reactive oxygen species and antioxidant activity in plants: a review. Fungal Divers. 54, 1-10. doi: 10.1007/s13225-012-0158-9

Hardy, R. W. F., Burns, R. C., and Parshall, G. W. (1971). The Biochemistry of N2 Fixation Bioinorganic Chemistry. Washington, DC: American Chemical Society.

Ikan, R., Ravid, U., Trosset, D., and Shulman, E. (1971). Ecdysterone: an insect molting hormone from Achyranthes aspera. Experientia 27, 504-505. doi: $10.1007 / \mathrm{BF} 02147560$

Jasim, B., Jimtha, C. J., Jyothis, M., and Radhakrishnan, E. K. (2013). Plant growth promoting potential of endophytic bacteria isolated from Piper nigrum. Plant Growth Regul. 71, 1-11. doi: 10.1007/s10725-013-9802-y

Jayanthi, P., and Lalitha, P. (2011). Reducing power of the solvent extracts of Eichhornia crassipes (Mart.) solms. Int. J. Pharm. Pharm. Sci. 3, 126-128.

Ji, S. H., Gururani, M. A., and Chun, S. C. (2014). Isolation and characterization of plant growth promoting endophytic diazotrophic bacteria from Korean rice cultivars. Microbiol. Res. 169, 83-98. doi: 10.1016/j.micres.2013.06.003

Kapoor, V. K., and Singh, H. (1966). Isolation of Betaine from Achyranthes aspera Linn. Indian J. Chem. 4, 461.

Katewa, S. S., and Arora, A. (2001). Hepato protective effects of certain ethanomedical plants from aravalli hills of Rajasthan. Indian Drugs 38, 332-335.

Kaur, G., and Reddy, M. S. (2013). Phosphate solubilizing rhizobacteria from an organic farm and their influence on the growth and yield of maize (Zea mays L.). J. Gen. Appl. Microbiol. 59, 295-303. doi: 10.2323/jgam.59.295

Khamna, S., Yokota, A., and Lumyong, S. (2009). Actinomycetes isolated from medicinal plant rhizospheric soils: diversity and screening of antifungal 
compounds, indole-3-acetic acid and siderophore production. World J. Microbiol. Biotechnol. 25, 649-655. doi: 10.1007/s11274-008-9933-x

Khamna, S., Yokota, A., Peberdy, J. F., and Lumyong, S. (2010). Indole-3-acetic acid production by Streptomyces sp. isolated from some Thai medicinal plant rhizosphere soils. Eur. Asian J. Biol. Sci. 4, 23-32. doi: 10.5053/ejobios.2010. 4.0.4

Khan, A. L., Halo, B. A., Elyassi, A., Sajid, A., Al-Hosni, K., Hussain, J., et al. (2016). Indole acetic acid and ACC deaminase from endophytic bacteria improves the growth of Solanum lycopersicum. Elec. J. Biotechnol. 21, 58-64. doi: 10.1016/j. ejbt.2016.02.001

Khastgir, H. N., Sen Gupta, S. K., and Sen Gupta, P. (1958). The sapogenin from seeds of Achyranthes aspera Linn. J. Indian Chem. Soc. 35, 693-694.

Kim, O. S., Cho, Y. J., Lee, K., Yoon, S. H., Kim, M., Na, H., et al. (2012). Introducing Ez Taxon-e: a prokaryotic 16S rRNA gene sequence database with phylotypes that represent uncultured species. Int. J. Syst. Evol. Microbiol. 62, 716-721. doi: 10.1099/ijs.0.038075-0

Koenig, R. A., and Johnson, C. R. (1942). Colorimetric determination of phosphorus in biological materials. Ind. Eng. Chem. Anal. 14, 155-156. doi: 10.1021/i560102a026

Kpomblekou, K., and Tabatabai, M. A. (1994). Effect of organic acids on release of phosphorus from phosphate rocks. Soil Sci. 158, 442-453. doi: 10.1097/ 00010694-199415860-00006

Kumar, A., Singh, R., Yadav, A., Giri, D. D., Singh, P. K., and Pandey, K. D. (2016). Isolation and characterization of bacterial endophytes of Curcuma longa L. 3 Biotech 6, 60-68. doi: 10.1007/s13205-016-0393-y

Kusari, S., Verma, V. C., Lamshoeft, M., and Spiteller, M. (2012). An endophytic fungus from Azadirachta indica A. Juss. that produces azadirachtin. World J. Microbiol. Biotechnol. 28, 1287-1294. doi: 10.1007/s11274-011-0876-2

Lamb, T. G., Tonkyn, D. W., and Kluepfel, D. A. (1996). Movement of Pseudomonas aureofaciens from the rhizosphere to aerial plant tissue. Can. J. Microbiol. 42, 1112-1120. doi: 10.1139/m96-143

Larkin, M. A., Blackshields, G., Brown, N. P., Chenna, R., McGettigan, P. A., McWilliam, H., et al. (2007). ClustalW and ClustalX version 2. Bioinformatics 23, 2947-2948. doi: 10.1093/bioinformatics/btm404

Loper, J. E., and Scroth, M. N. (1986). Influence of bacterial sources on indole3 acetic acid on root elongation of sugarbeet. Phytopathology 76, 386-389. doi: 10.1094/Phyto-76-386

Lugasi, A., Dworschak, E., Blazovics, A., and Kery, A. (1998). Antioxidant and free radical scavenging properties of squeezed juice from black radish (Raphanus sativus L., var. niger) root. Phytother. Res. 12, 502-506. doi: 10.1002/(SICI)10991573(199811)12:7<502::AID-PTR336>3.0.CO;2-I

Meyer, J. M., Van, V. T., Stintzi, A., Berge, O., and Winkelmann, G. (1995). Ornibactin production and transport properties in strains of Burkholderia vietnamiensis and Burkholderia cepacia (formerly Pseudomonas cepacia). Biometals 8, 309-317. doi: 10.1007/BF00141604

Mirza, B. S., and Rodrigues, J. L. (2012). Development of a direct isolation procedure for free-living diazotrophs under controlled hypoxic conditions. Appl. Environ. Microbiol. 78, 5542-5549. doi: 10.1128/AEM.00714-12

Misra, N., Gupta, G., Prabhat, N., and Jha, P. N. (2012). Assessment of mineral phosphate-solubilizing properties and molecular characterization of zinctolerant bacteria. J. Basic Microbiol. 52, 1-10. doi: 10.1002/jobm.201100257

Mohinder, K., Sanjeev, S., Vishal, R., and Girish, S. (2011). Potential of indigenous strains of Pseudomonas and Bacillus species for the production of plant growth regulators, viz., Auxins, Gibberellins and Cytokinins from carnation and medicinal plants. Progress. Hortic. 43, 56-60.

Nautiyal, C. S. (1999). An efficient microbiological growth medium for screening phosphate solubilizing microorganisms. FEMS Microbiol. Lett. 170, 265-270. doi: 10.1111/j.1574-6968.1999.tb13383.x

Neogi, N. C., Garg, R. D., and Rathor, R. S. (1970). Preliminary pharmacological studies on achyranthine. Indian J. Pharm. 32, 43-46.

Pandey, P., Sun, C. K., Chandra, P., and Gupta Maheshwari, D. K. (2005). Rhizosphere Competent Pseudomonas aeruginosa GRC1 produces characteristic siderophore and enhances growth of Indian Mustard (Brassica campestris). Curr. Microbiol. 51, 303-309. doi: 10.1007/s00284-005-0014-1

Payne, S. M. (1994). Detection, isolation and characterization of siderophores. Methods Enzymol. 235:329. doi: 10.1016/0076-6879(94)35151-1

Prasad, R., Kamal, S., Sharma, P. K., Oelmüller, R., and Varma, A. (2013). Root endophyte Piriformospora Indica DSM 11827 alters plant morphology, enhances biomass and antioxidant activity of medicinal plant Bacopa monnieri. J. Basic Microbiol. 53, 1016-1024. doi: 10.1002/jobm.201200367

Premono, M. E., Moawad, A. M., and Vlek, P. L. G. (1996). Effect of phosphatesolubilizing Pseudomonas putida on the growth of maize and its survival in the rhizosphere. Indones. J. Crop Sci. 11, 13-23.

Puri, S. C., Nazir, A., Chawla, R., Arora, R., Riyaz-ul-Hasan, S., and Amna, T. (2006). The endophytic fungus Trametes hirsuta as a novel alternative source of podophyl-lotoxin and related aryl tetralin lignans. J. Biotechnol. 122, 494-510. doi: 10.1016/j.jbiotec.2005.10.015

Radhapriya, P., Ramachandran, A., Anandham, R., and Mahalingam, S. (2015). Pseudomonas aeruginosa RRALC3 enhances the biomass, nutrient and carbon contents of Pongamia pinnata seedlings in degraded forest soil. PLOS ONE 10:e0139881. doi: 10.1371/journal.pone.0139881

Rameshwar, R. D. (2007). Essential oil constituents of Achyranthes aspera leaves. Indian Perfum. 51, 33-34.

Reinhardt, E. L., Ramos, P. L., Manfio, G. P., Barbosa, H. R., Pavan, C., and Moreira-Filho, C. A. (2008). Molecular characterization of nitrogen-fixing bacteria isolated from Brazilian agricultural plants at Sao Paulo State. Braz. J. Microbiol. 39, 414-422. doi: 10.1590/S1517-83822008000300002

Reinhold-Hurek, B., and Hurek, T. (1998). Interactions of gramineous plants with Azoarcus spp. and other diazotrophs: identification, localization and perspectives to study their function. Crit. Rev. Plant Sci. 17, 29-54. doi: 10.1016/ S0735-2689(98)00355-4

Ryan, R. P., Monchy, S., Cardinale, M., Taghavi, S., Crossman, L., Avison, M. B., et al. (2009). The versatility and adaptation of bacteria from the genus Stenotrophomonas. Nat. Rev. Microbiol. 7, 514-525. doi: 10.1038/nrmicro 2163

Sabharwal, N., Dhall, S., Chhibber, S., and Harjai, K. (2014). Molecular detection of virulence genes as markers in Pseudomonas aeruginosa isolated from urinary tract infections. Int. J. Mol. Epidemiol. Genet. 5, 125-134.

Sachdev, D. P., Chaudhari, H. G., Kasture, V. M., Dhavale, D. D., and Chopade, B. A. (2009). Isolation and characterization of indole acetic acid (IAA) producing Klebsiella pneumonia strains from rhizosphere of wheat (Triticum aestivum) and their effect on plant growth. Indian J. Exp. Biol. 47, 993-1000.

Sánchez-Moreno, C., Larrauri, J. A., and Sura-Calizto, F. (1999). Free radical scavenging capacity and inhibition of lipid oxidation of wines, grape juices and related polyphenolic constituents. Food Res. Int. 32, 407-412. doi: 10.1016/ S0963-9969(99)00097-6

Santoyo, G., Moreno-Hagelsieb, G., Orozco-Mosqueda Mdel, C., and Glick, B. R. (2016). Plant growth-promoting bacterial endophytes. Microbiol. Res. 183, 92-99. doi: 10.1016/j.micres.2015.11.008

Saxena, B., Modi, M., and Modi, V. V. (1986). Isolation and characterization of siderophores from Azospirillum lipoferum D-2. J. Gen. Microbiol. 132, 2219-2224. doi: 10.1099/00221287-132-8-2219

Sayyed, R. Z., Badgujar, M. D., Sonawane, H. M., Mhaske, M. M., and Chincholkar, S. B. (2005). Production of microbial iron chelators (Siderophores) by fluorescent pseudomonads. Indian J. Biotechnol. 4, 484-490.

Schulz, B., Boyle, C., Draeger, S., and Römmert, A. K. (2002). Endophytic fungi: a source of novel biologically active secondary metabolites. Mycol. Res. 106, 996-1004. doi: 10.1017/S0953756202006342

Schwyn, B., and Neilands, J. B. (1987). Universal chemical assay for the detection and determination of siderophore. Anal. Biochem. 160, 47-56. doi: 10.1016/ 0003-2697(87)90612-9

Seeley, H. W., and VanDemark, P. J. (1981). Microbes in Action: A Laboratory Manual of Microbiology, 3rd Edn. New York, NY: W.H. Freeman and Company.

Shanmugaiah, V., Mathivanan, N., and Varghese, B. (2010). Purification, crystal structure and antimicrobial activity of phenazine-1-carboxamide produced by a growth-promoting biocontrol bacterium, Pseudomonas aeruginosa MML2212. J. Appl. Microbiol. 108, 703-711. doi: 10.1111/j.1365-2672.2009.04466.x

Song, X., Wu, H., Yin, Z., Lian, M., and Yin, C. (2017). Endophytic bacteria isolated from Panax ginseng improves ginsenoside accumulation in adventitious ginseng root culture. Molecules 22:E837. doi: 10.3390/molecules220 60837

Srinivasan, K., Jagadish, L. K., Shenbhagaraman, R., and Muthumary, J. (2010). Antioxidant activity of endophytic fungus Phyllosticta sp. isolated from Guazumatomentosa. J. Phytol. Phytochem. 2, 37-41.

Strobel, G. A. (2003). Endophytes as sources of bioactive products. Microbes Infect. 5, 535-544. doi: 10.1016/S1286-4579(03)00073-X 
Strobel, G. A., and Daisy, B. (2003). Bioprospecting for microbial endophytesand their natural products. Microbiol. Mol. Biol. Rev. 67, 491-502. doi: 10.1128/ MMBR.67.4.491-502.2003

Subramaniam, R. (1961). Cystone - a vegetable diuretic. Antiseptic 2, 103-106.

Sun, Y., Cheng, Z., and Glick, B. R. (2009). The presence of a 1-aminocyclopropane-1-carboxylate (ACC) deaminase deletion mutation alters the physiology of the endophytic plant growth-promoting bacterium Burkholderia phytofirmans PsJN. FEMS Microbiol. Lett. 296, 131-136. doi: 10.1111/j.1574-6968.2009.01625.x

Tamura, K., Peterson, D., Peterson, N., Stecher, G., Nei, M., and Kumar, S. (2011). MEGA5: molecular evolutionary genetics analysis using maximum likelihood, evolutionary distance, and maximum parsimony methods. Mol. Biol. Evol. 28, 2731-2739. doi: 10.1093/molbev/msr121

Tanaka, A., Christensen, M. J., Takemoto, D., Pyoyun, P., and Scott, B. (2006). Reactive oxygen species play a role in regulating a fungus-perennial ryegrass mutualistic interaction. Plant Cell 18, 1052-1066. doi: 10.1105/tpc.105. 039263

Taule, C., Mareque, C., Barlocco, C., Hackembruch, F., Reis, V. M., Sicardi, M., et al. (2012). The contribution of nitrogen fixation to sugarcane (Saccharum officinarum L.), and the identification and characterization of part of the associated diazotrophic bacterial community. Plant Soil 356, 35-49. doi: 10.1007/s11104-011-1023-4
Thorne, E. T., Young, B. M., Young, G. M., Stevenson, J. F., Labavitch, J. M., Matthews, M. A., et al. (2006). The structure of xylem vessels in grapevine (Vitaceae) and a possible passive mechanism for the systemic spread of bacterial disease. Am. J. Bot. 93, 497-504. doi: 10.3732/ajb.93.4.497

Weisburg, W. G., Barns, D. M., Pelletier, D. A., and Lane, D. J. (1991). 16S ribosomal DNA amplification for phylogenetic study. J. Bacteriol. 73, 697-703. doi: 10.1128/jb.173.2.697-703.1991

Wettasinghe, M., and Shahidi, F. (1999). Antioxidant and free radical scavenging properties of ethanolic extracts of defatted borage (Borago officinalis L.) Seeds. Food Chem. 67, 399. doi: 10.1016/S0308-8146(99)00 137-5

Conflict of Interest Statement: The authors declare that the research was conducted in the absence of any commercial or financial relationships that could be construed as a potential conflict of interest.

Copyright (C) 2017 Devi, Pandey, Rawat, Sharma and Pandey. This is an open-access article distributed under the terms of the Creative Commons Attribution License (CC BY). The use, distribution or reproduction in other forums is permitted, provided the original author(s) or licensor are credited and that the original publication in this journal is cited, in accordance with accepted academic practice. No use, distribution or reproduction is permitted which does not comply with these terms. 